\title{
Research on the Influence Mechanism of Part-time Jobs on College Students' Sense of Social Responsibility
}

Kefei Tan ${ }^{1^{*}}$, Yingying $Q i^{2}$

${ }^{1}$ Beijing Normal University, Haidian District 100088, Beijing, China. E-mail: 461418024@qq.com

${ }^{2}$ Beijing Institute of Technology, Haidian District 100088, Beijing, China

Abstract: Sense of social responsibility, as an important part of ideological and political education for college students, is an ideological and moral quality that Chinese college students must possess. Part-time jobs, the basic way for college students to contact the society, may affect their sense of social responsibility. However, there has so far been little research on part-time jobs and college students' sense of social responsibility in China. This article analyzes the influence of duration and types of part-time jobs on college students' sense of social responsibility and the internal mechanism. It has been found that these two factors have a significant positive impact on college students' sense social responsibility, and the subjective evaluation of college students plays a moderating role in the duration of part-time jobs and their sense of social responsibility.

Keywords: Duration of Part-Time Jobs; Types of Part-Time Jobs; Sense of Social Responsibility; Subjective Evaluation

\section{Introduction}

College students taking part-time jobs has already become a common phenomenon in China ${ }^{[1]}$. A part-time job is an important way for them to get out of campus and contact the society. Previous studies mainly focused on the current situation of part-time jobs and college students' academic achievements and employment ${ }^{[2,3]}$, while there has been little research on the influence of part-time jobs on Chinese college students' psychological status. Based on this, this article explores the above topic from two aspects, namely the duration and types of part-time jobs ${ }^{[1]}$. Duration of part-time jobs refers to the time spent by college students for part-time jobs in a period of time, and types of part-time jobs are the number of jobs and the industry types that college students generally engage $\mathrm{in}^{[2]}$.

College students' sense of social responsibility refers to the attitude of a free college student towards the duties and missions for the state, the group and others ${ }^{[3]}$. College students' sense of social responsibility is influenced by individual psychology and behavior, that is to say, it is formed by their constant interaction with the external environment. Factors including interpersonal relationships, work tasks and social assistance can help them form and strengthen their own sense of social responsibility ${ }^{[4]}$. Social responsibility is the foundation of ideological and political education for Chinese college students, and concentratedly reflects their rationality and conscience ${ }^{[5]}$. College students with more parttime jobs have more opportunities to contact the society, and have stronger willingness to undertake social tasks and complete social practice. Therefore, this article puts forward Hypothesis 1 that the duration of part-time jobs positively affects college students' sense of social responsibility. In fact, many college students try or take on several part-time jobs. College students with various types of part-time jobs have a better understanding of all sectors of society, complete multiple social tasks, and thus have a stronger sense of responsibility for society and work. Therefore, Hypothesis 2 put forward in the article is that the diversity of part-time jobs positively affects the social responsibility of college students.

Subjective evaluation refers to the active overall reflection on the object's value, which exists all the time ${ }^{[6]}$.

Copyright (C) 2020 Kefei Tan et al

doi: 10.18282/le.v9i7.1472

This is an open-access article distributed under the terms of the Creative Commons Attribution Non-Commercial License

(http://creativecommons.org/licenses/by-nc/4.0/), which permits unrestricted non-commercial use, distribution, and reproduction in any medium, provided the original work is properly cited. 
College students' subjective evaluation of part-time jobs is a way to understand them formed during working, and can be different in each college student. College students who love part-time jobs and like to contact the society through them are more willing to spend time on part-time jobs. They may have more feelings for the society in the process and strengthen their sense of responsibility. By contrast, for those students who take on part-time jobs for earning living expenses or spending holidays, it is difficult for them to form social identification, which affects the improvement of their sense of social responsibility ${ }^{[7]}$. Therefore, this article proposes Hypothesis 3 that subjective evaluation of parttime jobs plays a moderating role in the influence of duration of part-time jobs on college students' sense of social responsibility.

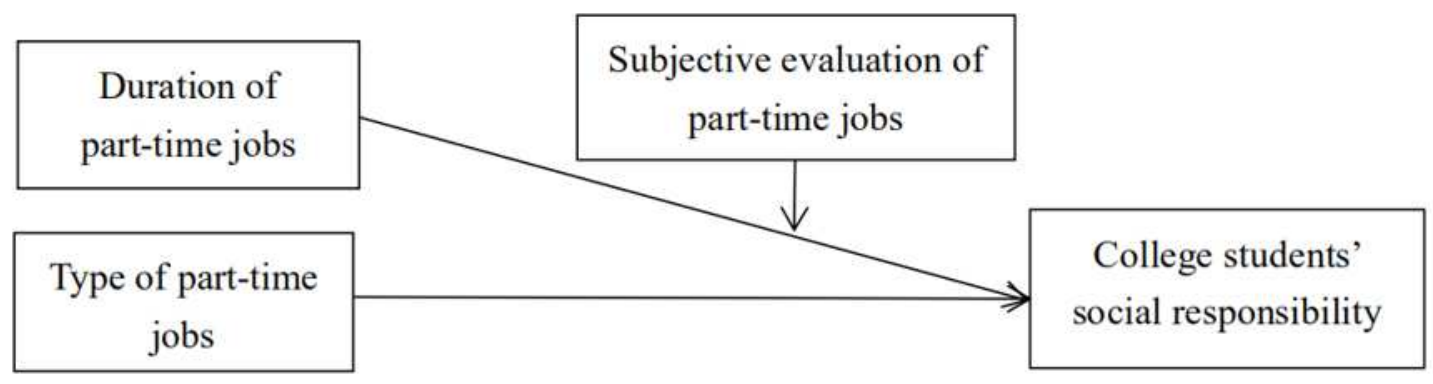

Figure 1 Theoretical model

\section{Research design}

\subsection{Research subjects}

In this study, 256 valid questionnaires were collected from undergraduates of Beijing Institute of Technology, Beijing Foreign Studies University and Minzu University of China who took on part-time jobs during winter vacation or had previous part-time experience, with a recovery rate of $85.3 \%$. The distribution of samples is $60.9 \%$ for boys and $39.1 \%$ for girls; freshmen accounted for $23.4 \%$, sophomores $33.2 \%$, juniors $35.1 \%$, and seniors $8.3 \%$; students from rural areas accounted for $37.1 \%$, from towns $32.8 \%$, and from cities $30.1 \%$.

\subsection{Research tools}

(1) Questionnaire about duration of part-time jobs. There are four questions in the questionnaire, including "You take on several part-time jobs in one semester" and "You spend a lot of time on part-time jobs in one semester". All of questions are scored by seven points $(1=$ strongly disagree, $7=$ strongly agree). Cronbach $\alpha$ of this study is 0.85 .

(2) Questionnaire about types of part-time jobs. The questionnaire consists of four questions, including "You do many types of part-time jobs in one semester" and "Tou take on part-time jobs in different industries in one semester". The four questions are scored by seven points $(1=$ strongly disagree, $7=$ strongly agree $)$. Cronbach $\alpha$ is 0.81 .

(3) Questionnaire about social responsibility. The questionnaire was compiled by Liu Haitao and Zheng Xue (2011) ${ }^{[8]}$, consisting of 66 items that are scored by five points ( $1=$ strongly disagree, $5=$ strongly agree). Cronbach $\alpha$ is 0.90 .

(4) Questionnaire about subjective evaluation of part-time jobs. Two questions are covered in the questionnaire, namely "Part-time jobs are beneficial to you" and "Part-time jobs can promote your development and progress". The two questions are scored by seven points ( $1=$ strongly disagree, $7=$ strongly agree $)$. The questionnaire is with the Cronbach $\alpha$ of 0.89 .

\section{Results}

\subsection{Descriptive statistics and analysis}

Descriptive statistics and analysis were carried out for each variable. The results are shown in Table 1. The duration of part-time jobs $(\mathrm{P}<0.01)$ and the diversity of part-time job types $(\mathrm{P}<0.05)$ have significant positive effects on college students' sense of social responsibility. Therefore, Hypothesis 1 and Hypothesis 2 are verified. 
Table 1 Descriptive statistical results and correlation matrix of each variable

\begin{tabular}{|c|c|c|c|c|c|c|c|}
\hline Variable & 1 & 2 & 3 & 4 & 5 & 6 & 7 \\
\hline Gender & 1 & & & & & & \\
\hline Grade & $-0.03^{*}$ & 1 & & & & & \\
\hline Place of birth & 0.09 & $0.02^{* *}$ & 1 & & & & \\
\hline Duration of part time jobs & 0.16 & -0.13 & -0.42 & 1 & & & \\
\hline Types of part time jobs & $0.26^{*}$ & 0.19 & -0.27 & 0.63 & 1 & & 1 \\
\hline $\begin{array}{c}\text { Subjective evaluation of } \\
\text { part-time jobs }\end{array}$ & $0.17^{* *}$ & -0.22 & -0.13 & 0.34 & 0.22 & & \\
\hline Social responsibility & -0.03 & -0.12 & 0.17 & $0.28^{* *}$ & $0.37^{*}$ & $0.19^{* *}$ & 1 \\
\hline
\end{tabular}

Note: ** denotes $\mathrm{P}<0.01$, * denotes $\mathrm{P}<0.05$

\subsection{Adjusting role of subjective evaluation in the effect of the duration of part-time jobs on college students' social responsibility}

In this article, model 1 (model 1 is a simple regulatory model) in SPSS compiled by Hayes (2013) ${ }^{[9]}$ is used to test the adjusting role of subjective evaluation in the effect of duration and types of part-time jobs on sense of social responsibility, in which duration of part-time is the independent variable $\mathrm{X}$, college students' social responsibility is the dependent variable $\mathrm{Y}$, subjective evaluation of part-time jobs is the adjusting variable $\mathrm{W}$, and gender, grade and place of birth of college students are the control variables. Analysis results of Bootstrap are shown in Table 2, which indicate that subjective evaluation of part-time jobs plays a significant adjusting role in the effect of duration of part-time jobs on college students' social responsibility. For college students with high subjective evaluation of part-time jobs (M + $1 \mathrm{SD}=5.2786$ ), duration of part-time jobs has a significant positive impact on college students' social responsibility. However, for those with low subjective evaluation of part-time jobs $(\mathrm{M}-1 \mathrm{SD}=3.5678)$, there is no significant relationship between the duration of part-time jobs and their sense of social responsibility. Therefore, the subjective evaluation of part-time jobs plays a positive adjusting role in the effect of duration of part-time jobs on college students' sense of social responsibility, that is, Hypothesis 3 of this article is verified.

Table 2 The adjusting role of subjective evaluation in the effect of duration of part-time jobs on college students' sense of social responsibility

\begin{tabular}{ccccccc}
\hline $\begin{array}{c}\text { Subjective evaluation of part-time } \\
\text { jobs }\end{array}$ & Effect & $S E$ & $t$ & $p$ & LLCI & ULCI \\
3.5678 & 0.8278 & 0.2588 & 2.3073 & 0.1277 & -0.0969 & 1.5586 \\
4.4232 & 0.6466 & 0.1547 & 2.5387 & 0.0089 & 0.1278 & 1.5654 \\
5.2786 & 0.4654 & 0.1569 & 1.8118 & 0.0074 & 0.2578 & 1.9887 \\
\hline
\end{tabular}

\section{Results and discussion}

This article discusses the influence of part-time jobs on college students' sense of social responsibility and the adjusting role of college students' subjective evaluation of part-time jobs from two aspects: the duration and types of part-time jobs. The results show that the two aspects have a significant positive impact on college students' sense of social responsibility. In other words, college students who spend more time on part-time jobs and take on various types of part-time jobs have stronger social responsibility than those who spend less time on part-time jobs and are used to taking on part-time jobs in the same industry.

In fact, it seems that college students who have more part-time jobs may not have a high sense of social responsibility, and may even show a lower sense of responsibility. Based on this, this article discusses the adjusting role of subjective evaluation. The results indicate that for college students with high subjective evaluation of part-time jobs, actively taking on more and different types of part-time jobs improve their sense of social responsibility, while for those 
with low subjective evaluation of part-time jobs, the duration and types of part-time jobs have no significant influence on their social responsibility. That is to say, with positive evaluation of part-time jobs, part-time jobs are conducive to improving their sense of social responsibility; however, for some college students who have negative evaluation of parttime jobs and only treat part-time jobs as a way to meet their own needs, part-time jobs have little influence on their sense of social responsibility. This conclusion can provide an important reference for college students to improve their sense of social responsibility through part-time jobs.

\section{Deficiencies and prospects}

First of all, this investigation is only targeted on undergraduates from several universities in Beijing, so the sample may not be representative. In the future research, samples of college students from more regions and universities should be collected to improve the ecological validity of the research.

Secondly, this study takes the duration and diversity of part-time jobs as independent variables to explore their influence on college students' sense of social responsibility. Future research can take the psychological impact mechanism of some new perspectives on college students as the topic, such as part-time salary and part-time professionalism.

\section{References}

1. Zhu Q. Investigation report on college students' part-time job (in Chinese). Divineland 2012; (35): 214.

2. Yao Y. Analysis on the characteristics of college students' part-time job (in Chinese). China Youth Study 2014; (1): 110-114.

3. Du J. Research on impact of part-time working on employment for graduates and their relevance-The case of undergraduates in Heifei City. Vocational and Technical Education 2015; (32): 49-52.

4. Jiang G, Ying X. Principles and practice of cultivating college students' sense of social responsibility (in Chinese). China Higher Education Research 2004; (3).

5. Peng D. Cultivating the sense of social responsibility of college students. Modern University Education 2003; (3): 41-44.

6. Liu R, Yan H. Subjective evaluation and analysis of its subjectivity and objectivity (in Chinese). Science and Technology and Dialectics 1994; (4): 34-37.

7. Du N, Jiang C, Liu X. The impact of challenging pressure of scientific research on academic achievement of academic postgraduates: The moderating effect based on subjective evaluation (in Chinese). Renmin University of China Educational Journal 2019; 33(1): 44-57.

8. Liu H, Zheng X, Nie Y. On the sense of college students' social responsibility and factors involved. Journal of Ningbo University (Educational Science Edition) 2011; 33(3): 35-39.

9. Hayes AF. Introduction to mediation, moderation, and conditional process analysis. Journal of Educational Measurement 2013; 51(3): 335-337. 